\title{
THE SHAPE OF VOLCANIC CONDUITS INFERRED FROM BUBBLE SIZE DISTRIBUTIONS
}

\author{
Sahand Hajimirza ${ }^{1 *}$, Helge M. Gonnermann ${ }^{1}$, and James E. Gardner ${ }^{2}$ \\ ${ }^{1}$ Department of Earth, Environmental and Planetary Sciences, Rice University, Houston, TX, USA \\ ${ }^{2}$ Jackson School of Geosciences, University of Texas at Austin, Austin, TX, USA
}

\begin{abstract}
The most intense known explosive volcanic eruptions on Earth are Plinian eruptions of silicic magma. Geospeedometers indicate that Plinian magma erupts from high pressure within the magma chamber at average speeds of $0.001-1 \mathrm{MPa} \mathrm{s}^{-1}$. Concurrently dissolved magmatic volatiles, predominantly water, nucleate about one quadrillion bubbles per cubic meter of melt, preserved as vesicles within tephra. Vesicles span several orders of magnitude in size, with power-law size distributions, and vesicularities of approximately $70 \pm 20 \%$. Together these observations have never been explained in a self-consistent manner. Here we demonstrate that the integration of these observations requires that bubble nucleation commences as magma ascends from within the chamber and continues until the magma fragments to produce tephra. We substantiate experimentally that nucleation in rhyolitic melt can occur continuously over prolonged time intervals. We then use integrated modeling of bubble nucleation and fluid dynamics of magma ascent to demonstrate that bubble size distributions in Plinian pyroclasts are the product of continuous nucleation throughout magma ascent at average decompression rates that are consistent with geospeedometers. A necessary requirement is that the transition from magma chamber to volcanic conduit is gradual, resembling a cupola that narrows upward into a conduit, which in turn continues to decrease in size with distance above the chamber.
\end{abstract}

\section{INTRODUCTION}

The abundant bubbles that form during magma ascent in the conduit power explosive volcanic eruptions. The supercritical aqueous fluid within bubbles, sometimes referred to as vapor or gas, is of lower density than the silicate melt from whence it exsolves $[1,2]$. By virtue of conservation of mass the volume of magma, that is silicate melt plus bubbles, increases as it rises toward the Earth's surface. This results in magma acceleration and expansion [3, 4]. During explosive eruptions the associated strains and strain rates will cause the magma to fragment, which in turn is a defining process of explosive silicic eruptions $[5,6$, 7].

Bubbles form by exsolution of dissolved magmatic volatiles as a consequence of decreasing magma pressure en route to the surface [8]. Volatile exsolution involves the simultaneous nucleation of new bubbles and diffusion from the melt into existing bubbles $[9,10]$.Volatiles become supersaturated as magma pressure decreases, inducing bubble nucleation $[8,10,11]$. Diffusion of volatiles, in particular $\mathrm{H}_{2} \mathrm{O}$, from the melt into existing bubbles causes bubbles to grow $[9,10]$, while at the same time decreasing supersaturation and increasing magma viscosity [12]. A dynamical feedback between decompression, bubble nucleation and diffusion ensues [10,13]. A record of these intertwined processes is the bubble size distribution (BSD), preserved in pyroclasts as the vesicle size distribution (VSD) [14, 15, 16, 17, 18, 19].

VSDs have been used to infer observationally inaccessible subsurface conditions during eruptive magma ascent $[14,15,16$, $17,18,20,19,21,22,23]$. To date there have been no quantitative models, integrating bubble nucleation and growth within a fluid dynamical model of magma ascent and decompression, which are capable of reproducing VSDs and thereby providing quantitative constraints on explosive eruptions. Moreover, exist- ing models that predict the overall number density of bubbles tend to infer magma decompression rates that are at odds with geospeedometers which yield orders of magnitude lower decompression rates [24, 25]. Here we resolve both deficiencies using numerical modeling of eruptive magma ascent and vesiculation, with the latter encompassing bubble nucleation and growth. Our simulated BSDs reproduce observed VSDs at average decompression rates that are consistent with geospeedometers.

\section{ApProAch}

\subsection{Continuous nucleation}

The continuous power-law vesicle size distributions in pyroclasts are thought to be the result of protracted bubble nucleation throughout magma ascent [20,21]. Although such continuous nucleation is in principle consistent with nucleation theory [10, 26, 27], wide VSDs as observed in Plinian pyroclasts are usually not produced in nucleation experiments [28, 29, 30]. Moreover, because it is nearly impossible to directly observe bubble nucleation during these high pressure and temperature experiments, continuous nucleation cannot be validated through direct observation.

The objective of our experiments is to validate that bubble nucleation during decompression of hydrated rhyolitic melt is indeed continuous. The experiments consisted of three steps [31] (Supplementary Table 1; Supplementary Figure 1). First samples were hydrated at an initial pressure, $P_{\mathrm{i}}=160-250 \mathrm{MPa}$, and temperature, $T=850^{\circ} \mathrm{C}$, until equilibrium was achieved. Next, samples were decompressed over a time interval, $1 \mathrm{~s} \leq t_{\mathrm{d}} \leq 50 \mathrm{~s}$, to their final pressure, $P_{\mathrm{f}}=10-100 \mathrm{MPa}$. In the final step, samples were held at the final pressure for a duration of annealing time, $0 \mathrm{~s} \leq t_{\text {post }} \leq 120 \mathrm{~s}$, and then were rapidly quenched. Bubble number density (BND) was subsequently measured in thin 


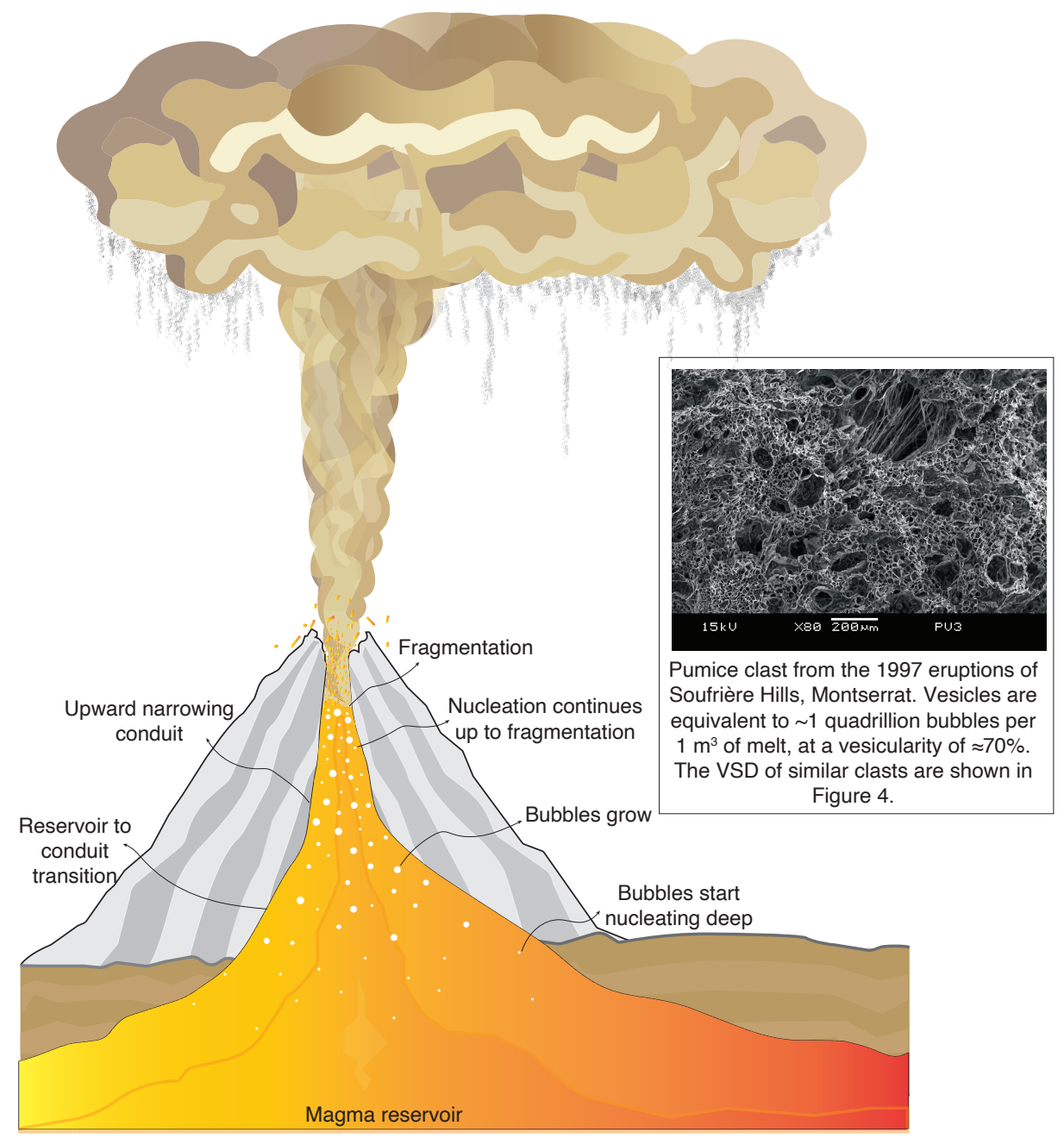

Figure 1: Schematic diagram of the magma storage-conduit system envisaged during Plinian eruptions. Bubbles begin nucleating during magma withdrawal within the upper reaches (cupola) of the magma reservoir. Nucleation continues up to the point of magma fragmentation. Bubble size distributions, preserved in Plinian pyroclasts, are produced by a continuous and protracted nucleation process. Inset: scanning electron microscope image of a pumice from the 1997 eruption of Soufrière Hills, Montserrat (courtesy T. Giachettii).

sections of the quenched samples. The experiments were divided into six suites for each of which saturation pressure, decompression rate, and final pressure were closely similar. Within each suite samples were quenched at different $t_{\text {post }}$. If nucleation was ongoing during the annealing period, then samples within a given suite should have a linear correlation between $t_{\text {post }}$ and bubble number density.

\subsection{Modeling of magma ascent and bubble nucleation}

We simulate the fluid dynamics of eruptive magma ascent together with bubble nucleation and growth during Plinian eruptions, Figure 1 (see Methods for details). We assume a cylindrical conduit whose radius may change with depth and solve the steady mass and momentum conservation equations for the change in magma velocity and pressure with depth. The latter provides the boundary condition for the integrated sub-grid bubble nucleation and growth model. We consider $\mathrm{H}_{2} \mathrm{O}$ the most abundant volatile phase [32] and driver of bubble nucleation $[8,10]$ and assume heterogeneous nucleation [24, 25]. Our objective is to test the hypothesis that VSDs in Plinian pyroclasts are the product of continuous nucleation during magma ascent. Each simulation is therefore constrained to maintain sufficient supersaturation for nucleation. This is achieved by varying conduit size, such that at any given depth the magma decompression rate is slightly greater than the inverse characteristic diffusion time. Conceptually this approach is similar that employed in conduit models with a near-lithostatic magma pressure [33]. Thus, aside from predicting decompression rate, bubble number density and size distribution, the model also predicts conduit radius as a function of depth. 


\section{Results}

\subsection{Experimental verification of continuous bubble nucleation}

Our experiments produced bubble number densities that vary over 5 orders of magnitude $\left(10^{8}-10^{13}\right.$ bubbles per $\mathrm{m}^{3}$ of melt). Although supersaturation, defined as the difference between the initial and final pressures, drives nucleation, experimental BNDs are not correlated with supersaturation (Supplementary Figure 2 ). Instead, experiments within a suite produced BNDs that vary by up to 2 orders of magnitude and are correlated with the annealing time, $t_{\text {post }}$.

Because BNDs among various suites vary significantly, a synthesis of all experiments requires non-dimensionalization of bubble number density and annealing time. $t_{\text {post }}$ is scaled by the nucleation time scale, $\tau$, which represents the time that nucleation rate drops by one e-folding time. $N_{\text {post }}$, which represents BND for bubbles that are nucleated during annealing time, is non-dimensionalized by the equilibrium bubble number density, $N_{\text {eq }}$, the final bubble number density that a sample could have attained under the given experimental conditions.

For each experimental suite $N_{\text {eq }}$ and $\tau$ are estimated by minimizing the difference between predicted (equation 33) and observed bubble number densities (Supplementary Figure 3). The resultant values, shown in Supplementary Table 2, are similar for samples within a given experimental suite and predominately depend on the initial and final pressures. Non-dimensional BND is predicted to increase linearly between $0 \leq t_{\text {post }} \leq \tau$, after which it reaches its maximum value [26]. Thus, non-dimensionalization should collapse all experiments during which nucleation was continuous onto the predicted line by equation (33). Figure 2 shows that this is the case within the expected experimental variability. Given that the maximum value of $\tau$ in our experiments was $\approx 1000$ s, our experiments substantiate that bubble nucleation in rhyolitic melt can be a continuous process for at least that long.

\subsection{Key results for bubble nucleation during magma ascent}

Figures 3 and 4 show simulation results for a typical Plinian discharge rate of $Q=5 \times 10^{7} \mathrm{~kg} / \mathrm{s}$, an initial $\mathrm{H}_{2} \mathrm{O}$ saturation at a pressure of $145 \mathrm{MPa}$, and choked flow at the surface [33, 34] Similar results are obtained for different discharge rates and/or saturation pressures. The simulations shown in blue have no bubbles prior to eruption, whereas those in red have an initial volume fraction of 0.03 bubbles. The simulations shown in thick blue and red lines are base cases. They were obtained by adjusting conduit radius such that the decompression rate is greater than the inverse characteristic $\mathrm{H}_{2} \mathrm{O}$ diffusion time at all depths above where the first bubbles nucleate (for more details see equation (30) in Methods). No other parameters were adjusted to obtain the simulation results shown. The thin blue and red simulations illustrate model sensitivity to variations in predicted conduit radii. They were obtained for conduit radii that are shifted to smaller and larger values relative to the base cases. The key result is an upward narrowing conduit as a necessary requirement for continuous nucleation.

Thus, in all cases the BSDs shown in Figure 4 are model predictions that were obtained by constraining conduit radius such that the decompression rate is slightly greater than the inverse characteristic $\mathrm{H}_{2} \mathrm{O}$ diffusion time. Variations in conduit radius

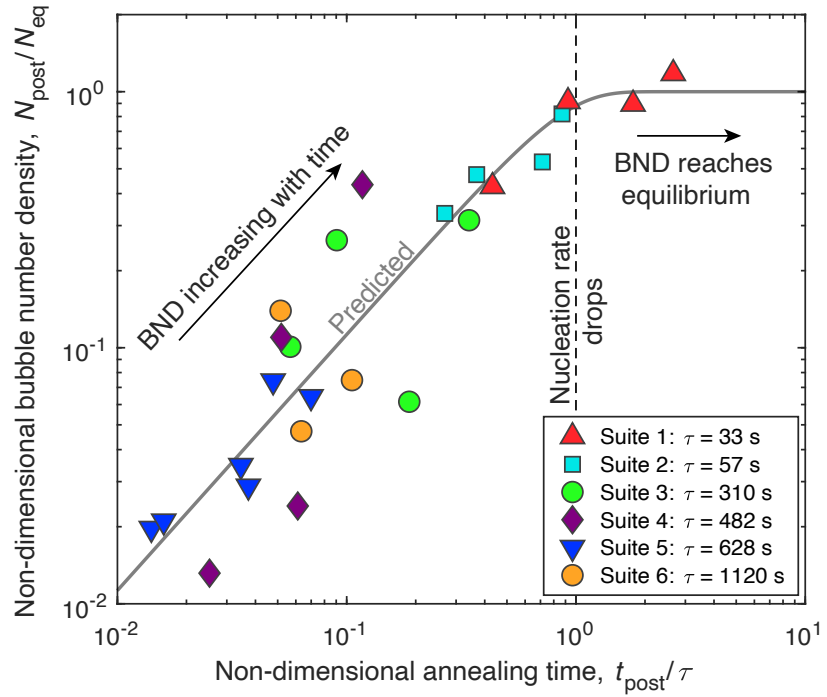

Figure 2: Continuous bubble nucleation in decompression experiments. Data are represented in non-dimensional variables. The sample annealing time is non-dimensionalized by the nucleation time scale, $\tau$. Bubble number density is non-dimensionalized by the equilibrium value of the given sample suite, $N_{\text {eq }}$ (Equation (36)). The values of $\tau$ and $N_{\mathrm{eq}}$ are constant for each experimental suite (Table S2). All experiments fall along the trend expected for continuous nucleation, demonstrating that that bubble nucleation in rhyolitic melts is continuous across a wide range in conditions. Given the range of $\tau_{n}$ in our experiments, nucleation was continuous for at least 1000 seconds.

primarily affect decompression rate, fragmentation depth, and bubble number density, but still yield results for all relevant parameters that are well within range of observed values for Plinian eruptions. At very low nucleation rates $\left(J<10^{9} \mathrm{~m}^{-3}\right.$ $\mathrm{s}^{-1}$ ) nucleation is quite sensitive to small variations in conduit radius (decompression rate), resulting in oscillations in nucleation rate. These become, however, quickly damped out as bubble number densities, $N_{\mathrm{m}}$ exceed values of $10^{10}$ bubbles per $\mathrm{m}^{-3}$ of melt. For all cases shown, the match between predicted bubble size distributions and those measured in Plinian pyroclasts is remarkable and suggests that bubble nucleation during eruptions is indeed continuous throughout magma ascent, presumably commencing shortly above the magma chamber or perhaps already during magma withdrawal from the chamber.

\subsection{Simulation details}

As bubbles nucleate and grow, the distance between bubbles decreases. Consequently the characteristic diffusion rate, which scales as the inverse squared distance between bubbles, increases. To maintain supersaturation and nucleation decompression rate has to increases with distance above the magma reservoir. An upward narrowing conduit increases the average magma velocity, which increases both the hydrostatic and dynamic components of the momentum balance. At the same time, due to bubble nucleation and growth, the average water concentration within the melt decreases as the magma rises to shallower depths. Even- 

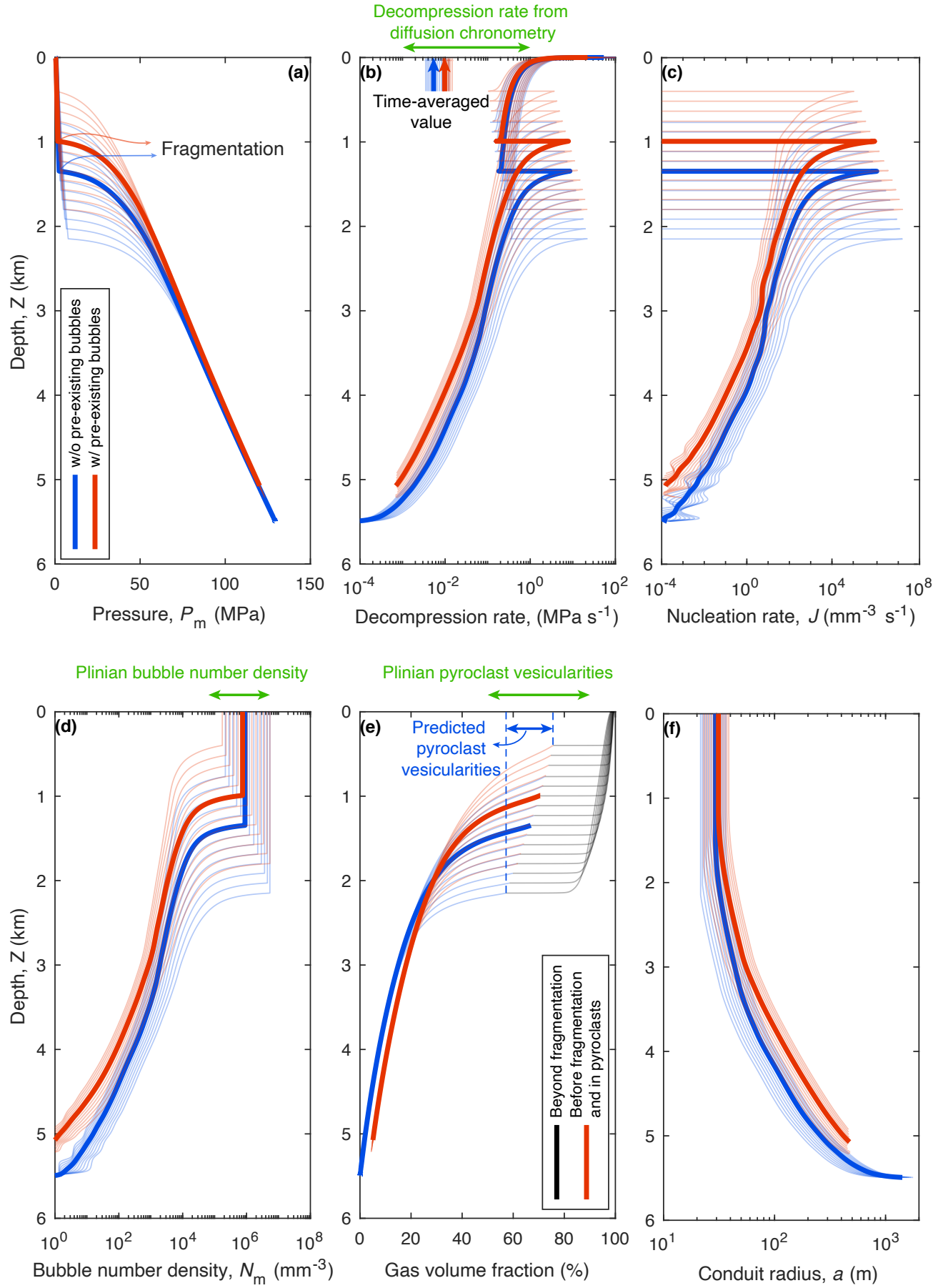

Figure 3: Simulation results for a mass discharge rate of $5 \times 10^{7} \mathrm{~kg} / \mathrm{s}$ and $\mathrm{H}_{2} \mathrm{O}$ saturation pressure of $145 \mathrm{MPa}$. The blue and red curves represent simulations with three percent and without pre-existing bubbles, respectively. The results are shown from nucleation onset until magma reaches the surface. (a-b) Pressure decreases as magma ascends, due to hydrostatic and viscous pressure loss. (c) As a consequence $\mathrm{H}_{2} \mathrm{O}$ becomes supersaturated, causing heterogeneous bubble nucleation. (d) Consequently bubble number density increases as magma ascends to shallower depths. (e) Nucleation, in conjunction with diffusion of $\mathrm{H}_{2} \mathrm{O}$ into existing bubbles, as well as decompression of the fluid inside bubbles, results in an increase of volume fraction of exsolved $\mathrm{H}_{2} \mathrm{O}$. (a-e) At the depth of magma fragmentation there is an abrupt change in the trend of the aforementioned variables. (f) Conduit radius as a function of depth required to obtain continuous nucleation during magma ascent.

tually, this results in a sufficiently large increase in viscosity, itive feedback between decompression rate, water exsolution such that the pressure loss due to wall friction results in a pos- and viscosity. In Figures $3 \mathrm{a}$ and $3 \mathrm{~b}$ this manifests itself as the 
pronounced curvature in $P_{\mathrm{m}}$ and decompression rate prior to fragmentation. the rapidly increasing decompression rate results in increasing supersaturation and, hence, nucleation rate, bubble number density, and volume fraction of bubbles (Figures 3c, 3d and $3 \mathrm{e}$, respectively). Once the feedback between decompression rate, water exsolution and viscosity becomes dominant the conduit radius no longer needs to decrease in order to maintain supersaturation (Figure 3f). Instead, It is this runaway feedback that produces the high overall bubble number density as well as the small bubble diameter tail in the size distribution. The latter can also be found in Plinian pyroclasts, where it is associated with a decrease in the power-law exponent of the distribution with decreasing bubble diameter (Figure 4).

Upon fragmentation gas pressure inside bubbles quickly equalizes with magma pressure, as a consequence of permeable gas flow from pyroclasts into the surrounding fractures and producing a rapid increase in gas volume fraction, as the gas-pyroclast mixture expands (Figure 3e). Outgassing of the pyroclasts is simulated using a pore-pressure relaxation rate (equation (23) in Methods), based on measured pyroclast permeabilities [35] At the same time decompression rate decreases because of the abrupt change in viscosity, which is much lower for the gas-pyroclast mixture above fragmentation than for the bubbly magma (Figure $3 b$ ). As a consequence there is rapid water diffusion out of the melt and loss of supersaturation conditions. $\mathrm{H}_{2} \mathrm{O}$ continues to exsolve en route to the surface, contributing together with the expansion of the exsolved $\mathrm{H}_{2} \mathrm{O}$ to the continued increase in gas volume fraction (Figure $3 \mathrm{e}$ ). The mixture of gas-pyroclasts thus accelerates and reach choked flow conditions at the conduit exit (equation (27)), as commonly assumed in eruption models $[3,33,36]$. We assume that bubbles do not nucleate and grow within the pyroclasts that is after fragmentation. In other words, any remaining dissolved $\mathrm{H}_{2} \mathrm{O}$ exsolves through diffusion into existing bubbles and then enters the gas phase that surrounds pyroclasts by permeable flow within the pyroclasts [37].

\section{Discussion}

Continuous nucleation reconciles multiple observations from Plinian eruptions. When incorporated into numerical models for eruptive magma ascent, predicted bubble number number densities and vesicularities are within the range of Plinian pyroclasts (Figure 3). Moreover, the predicted BSDs also mirror those measured in Plinian pyroclasts (Figure 4). They span several orders of magnitude in size and the observed change in power-law exponents from $d=3-4$ to $d=1-2$ with decreasing vesicle size $[15,19,16,14]$ also exists in the simulated BSDs This change in slope of the size distribution can be attributed to the aforementioned accelerating feedback between viscous pressure loss and nucleation.

Although magma decompression rate increases continuously as magma rises toward the level of fragmentation, the predicted time-averaged decompression rates $\sim 10^{-2} \mathrm{MPa} \mathrm{s}^{-1}$ are well within the $0.001-1 \mathrm{MPa} \mathrm{s}^{-1}$ range of diffusion chronometers [38]. Thus, continuous nucleation fully closes the large previous gap in decompression rate estimates between diffusion chronometers and bubble nucleation models [24, 38, 27].

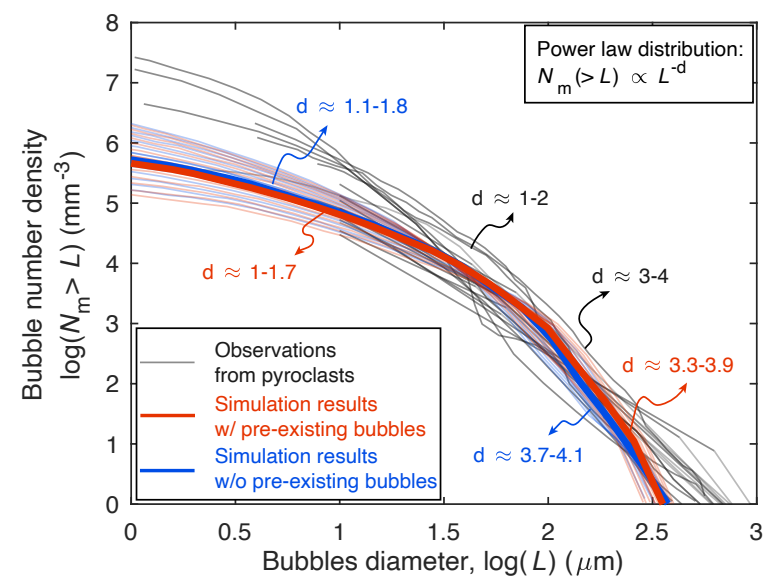

Figure 4: Simulated bubble size distributions corresponding to the simulations of Figure 3 (red and blue curves), together with distributions from Plinian pyroclasts (gray curves). The latter are from the 1912 Novarupta eruption in Alaska[15], the 1875 Askja eruption in Iceland[16], the 2008 Chaiten eruption in Chile[19], and the 7.7 ka Mazama eruption, Oregon[14]. Plinian BSDs have been subdivided into two overlapping power law distributions with exponents of $d \approx 3-4$ and $d \approx 1-2$. In the simulations the latter size fraction of the distribution represents bubbles nucleated during the rapid increase in decompression rate in the depth range where the feedback between water exsolution and viscous pressure loss accelerates up to fragmentation.

The overarching result, however, is the necessary requirement that conduits widen with depth from a few 10 s of $\mathrm{m}$ at shallow depths to radii of $\sim 100$ s to $1000 \mathrm{~m}$ at $\mathrm{H}_{2} \mathrm{O}$ saturation depths. The magma reservoir-conduit complex thus resembles in shape a wine decanter with a wide base. Alternatively, one could view our simulated 'conduits' as the top of magma chambers that form broad cupolas which narrow upward into the developing conduit. The implication would be that bubbles start nucleating during magma withdrawal within the upper reaches of the magma chamber, with the resultant decompression rates spanning a wide range in values [39]. Motivated by this consideration we also examined the role of pre-existing bubbles prior to eruption [40]. Although pre-existing bubbles somewhat reduces the required conduit widening, they do not affect the essential character of the simulation results, including the BSDs.

We have demonstrated experimentally that bubble nucleation in rhyolitic melt can be a continuous process over time intervals of at least thousands of seconds. Building upon this insight, numerical simulations of bubble nucleation and growth, in conjunction with the fluid dynamics of eruptive magma ascent, show that vesicle size distributions in Plinian pyroclasts can be explained by continuous heterogenous bubble nucleation during magma ascent. The ensuing average magma decompression rates are consistent with diffusion-chronometry geospeedometers. Moreover, the resultant bubble size distributions are similar to vesicle size distributions measured in Plinian pyroclasts, regardless of whether there already are bubbles in the magma prior to eruption or not. A necessary condition is that conduits widen with depth and transition via a broad cupola into the upper reaches of magma reservoirs. 


\section{Methods}

We model the one-dimensional fluid dynamics of steady magma flow in the volcanic conduit, coupled with the nucleation and growth of $\mathrm{H}_{2} \mathrm{O}$ bubbles. Simulations start at $\mathrm{H}_{2} \mathrm{O}$ saturation, corresponding to a pressure, $P_{\mathrm{H}_{2} \mathrm{O}}$. Assuming a constant lithostatic pressure gradient of $\rho_{\text {rock }} g$, where $\rho_{\text {rock }}=2400 \mathrm{~kg} / \mathrm{m}^{3}$ is rock density and $g$ is gravity acceleration, the saturation pressure $P_{\mathrm{H}_{2} \mathrm{O}}$ corresponds to a depth, $Z_{0}=$ $P_{\mathrm{H}_{2} \mathrm{O}} /\left(\rho_{\text {rock }} g\right)$. Simulations end when magma reaches the surface at $Z=0$. As magma flows up the volcanic conduit magma pressure, $P_{\mathrm{m}}$, decreases due to hydrostatic and viscous pressure loss. The magma thus becomes supersaturated in $\mathrm{H}_{2} \mathrm{O}$, resulting in bubble nucleation. At the same time $\mathrm{H}_{2} \mathrm{O}$ diffuses from the melt into existing bubbles, as they grow. The fluid dynamics of magma ascent are coupled with the nucleation and growth of bubbles through magma pressure $P_{m}$, which provides a depth-varying boundary condition for the bubble nucleation and growth calculations. In the subsequent sections we will detail the methodologies for employed to model magma flow in the conduit as well as bubble nucleation and growth within the ascending magma.

\subsection{Magma flow in the conduit}

We assume a vertical cylindrical conduit, whose radius can vary with depth, $Z$. We assume the flow is steady because the duration of magma ascent is much shorter than the duration of Plinian eruptions [41]. We assume flow is one dimensional and integrate flow properties over the cross-sectional area of the conduit. Below the level of fragmentation we define magma as the mixture of silicate melt and $\mathrm{H}_{2} \mathrm{O}$ bubbles. Above the level of fragmentation magma is the mixture of continuous $\mathrm{H}_{2} \mathrm{O}$ vapor with suspended fragments of vesicular magma, that is pyroclasts Throughout the relative velocity between the two phases (melt and $\mathrm{H}_{2} \mathrm{O}$ vapor/fluid) is neglected. Below fragmentation this is justified because the buoyant rise velocity of bubbles is negligible, given the large melt viscosity [33]. Above fragmentation it is a commonly employed approximation $[3,33]$ and one that does not affect the salient results of our simulations in any significant manner. The properties of the mixture that is of the magma, are the volumetric average of the two phases The flow is furthermore assumed to be isothermal, another common approximation that dose not significantly impact bubble nucleation rate [36].

With these assumptions, conservation of mass and momentum are $[3,33]$

$$
\frac{\partial\left(\rho_{\mathrm{m}} u A\right)}{\partial z}=0,
$$

and

$$
\rho_{\mathrm{m}} u \frac{\partial u}{\partial z}=-\frac{\partial p_{\mathrm{m}}}{\partial z}-\rho_{\mathrm{m}} g-F_{\text {fric }},
$$

respectively. Here $\rho$ is magma density, averaged over liquid and gas phases,

$$
\rho=\phi \rho_{\mathrm{g}}+(1-\phi) \rho_{\mathrm{l}} \text {. }
$$

$\phi$ is the volume fraction of bubbles, $u$ is magma ascent rate, $A=\pi a^{2}$ is the conduit cross sectional area, $a$ is conduit radius, and $\rho_{\mathrm{g}}$ and $\rho_{1}=2400 \mathrm{~kg} / \mathrm{m}^{3}$ are gas and melt densities respectively. $F_{\text {fric }}$ is the frictional pressure loss estimated as $\rho_{\mathrm{m}} u^{2} f / a$ where $f$ is the friction factor. Before fragmentation $f=16 / R e+f_{0}$ and after fragmentation $f=f_{0} . R e=2 \rho_{\mathrm{m}} u a / \eta$ is the Reynolds number, $\eta$ is the viscosity of the mixture, and $f_{0}$ is a factor related to conduit wall's roughness and assumed to be 0.0025 [33].

By substituting equation (1) into (2) one obtains

$$
-\frac{\partial p_{\mathrm{m}}}{\partial z}=\rho_{\mathrm{m}} g+F_{\text {fric }}-\frac{\rho_{\mathrm{m}} u^{2}}{A} \frac{\partial A}{\partial z}-u^{2} \frac{\partial \rho_{\mathrm{m}}}{\partial z} .
$$

Here

$$
\frac{\partial \rho_{\mathrm{m}}}{\partial z}=\frac{\partial \rho_{\mathrm{m}}}{\partial p_{\mathrm{m}}} \frac{\partial p_{\mathrm{m}}}{\partial z}
$$

and given that under constant entropy

$$
\frac{\partial \rho_{\mathrm{m}}}{\partial p_{\mathrm{m}}}=c^{2},
$$

where $c$ is the speed of sound within the magma. Equation (4) can thus be simplified to

$$
-\frac{\partial p_{\mathrm{m}}}{\partial z}=\frac{\rho_{\mathrm{m}} g+F_{\text {fric }}-\frac{\rho_{\mathrm{m}} u^{2}}{A} \frac{\partial A}{\partial z}}{1-M^{2}},
$$

where $M=u / c$ is the Mach number of the mixture. The sound speed before fragmentation is estimated from $c^{2}=K_{\mathrm{m}} / \rho_{\mathrm{m}}$ where $K_{\mathrm{m}}$ is bulk modulus of the mixture

$$
\frac{1}{K_{\mathrm{m}}}=\frac{\phi}{K_{\mathrm{g}}}+\frac{1-\phi}{K_{\mathrm{l}}}
$$

The bulk modulus of the gas phase, $K_{\mathrm{g}}$, is calculated from equation of state [2] and the liquid is assumed to be incompressible [36]. The sound speed of the gas-pyroclast mixture after fragmentation is assumed to be equivalent to the sound speed in the gas phase [34]. Alternate models for the sound speed of the gas-pyroclast mixture [33] do not affect the outcome of the model results in terms of bubble nucleation, which occurs prior to fragmentation.

\subsection{Bubble nucleation and growth}

We assume $\mathrm{H}_{2} \mathrm{O}$ is the only volatile phase because it is most abundant and controls final bubble number density [32]. $\mathrm{H}_{2} \mathrm{O}$ exsolves through bubble nucleation and diffusion into already nucleated bubbles. We assume nucleation is heterogeneous and facilitated by abundant pre-existing magnetite nanolites [24, 25]. We use the far field approximation to calculate $\mathrm{H}_{2} \mathrm{O}$ diffusion from melt into bubbles [10]. Lastly, we assume that permeable escape of $\mathrm{H}_{2} \mathrm{O}$ vapor from the bubbles is negligible before magma fragments, but account for it after fragmentation. The bubble nucleation and growth model is in the Langrangian frame of reference. It is integrated to the steady state equations for magma flow in the conduit, which is in Eulerian frame of reference, by considering $d / d t=u \partial / \partial z$.

The number of bubbles in volcanic systems is too high to track growth of each individual bubble. We therefore use the method of moments to calculate the evolution of the bubble population [10]. The corresponding moments of the population, $\mu$, are defined as

$$
\mu_{k}(t)=\int_{0}^{\infty} R^{k} \Lambda(R, t) d R
$$

where $R$ is the bubbe radius, $\Lambda(R, t)$ is the bubble population per unit volume of melt within the interval of $R$ and $R+d R$, and subscript $\mathrm{k}=0-3$ refers to the order of the moment. Each moment refers to a measurable characteristic quantity [10]. $\mu_{0}$ is the bubble number density, that is the number of bubbles per unit volume of melt, $\mu_{1}$ is the sum of bubbles radius, $4 \pi \mu_{2}$ is the total surface area of bubbles, and $4 / 3 \pi \mu_{3}$ is the total volume of bubbles. The evolution of moments through time is given by

$$
\frac{d \mu_{0}}{d t}=J
$$

and for , $\mathrm{k} \geq 1$, by

$$
\frac{d \mu_{k}}{d t}=k G(\hat{R}) \mu_{k-1}+J R_{\mathrm{c}}^{k}
$$

where $J$ is nucleation rate of bubbles, $G(\hat{R})$ is the growth rate of bubbles assumed to be equal for all bubbles and equivalent to the growth rate of a bubble with mean bubble size, $\hat{R}=\mu_{1} / \mu_{0}$, and $R_{\mathrm{c}}$ is the critical size for nucleating bubbles. 


\subsubsection{Below fragmentation}

We use classical nucleation theory to estimate nucleation rate of stable bubble nuclei as a function of supersaturation pressure. Nucleation rate of stable bubbles are [11]

$$
J=J_{0} \exp \left(-\frac{W}{k_{\mathrm{B}} T}\right),
$$

and bubbles are stable if they are larger than a critical size, $R_{\mathrm{c}}$, given by

$$
R_{\mathrm{c}}=\frac{2 \gamma}{p_{\mathrm{n}}-p_{\mathrm{m}}} .
$$

Here $T$ is the absolute temperature, $k_{\mathrm{B}}$ is the Boltzmann constant, $\gamma$ is the surface tension of bubble nuclei, $P_{\mathrm{n}}$ is the pressure inside a bubble nucleus, and $P_{\mathrm{m}}$ is pressure in the mixture. $p_{\mathrm{n}}$ is related to the saturation pressure of volatiles, $p_{\text {sat }}$, through [42]

$$
f\left(p_{\mathrm{n}}, T\right) p_{\mathrm{n}}=f\left(p_{\mathrm{sat}}, T\right) p_{\mathrm{sat}} e^{\Omega\left(p_{\mathrm{m}}-p_{\mathrm{sat}}\right) / k_{\mathrm{B}} T},
$$

where $f(p, T)$ is the fugacity coefficient, and $\Omega$ is the volume of volatile molecules. $W$ is the change in free energy as a result of nucleation of a bubble and is given by

$$
W=\frac{16 \pi \gamma^{3}}{3\left(p_{\mathrm{n}}-p_{\mathrm{m}}\right)^{2}} \alpha,
$$

where $\alpha$ is the heterogeneous nucleation factor and depends on the contact angle, $\theta$, between bubble nuclei and pre-existing crystals. It is defined as

$$
\alpha=\frac{(2-\cos \theta)(1+\cos \theta)^{2}}{4},
$$

and we assume nucleation is facilitated by magnetite crystals with $\theta=145^{\circ}[43,44]$.

The pre-exponential factor, $J_{0}$, in equation (12) is defined as

$$
J_{0}=\frac{2 \Omega n_{0}^{2} D}{a_{0}} \sqrt{\frac{\gamma}{k_{\mathrm{B}} T}},
$$

where $n_{0}$ is the concentration of volatiles molecules in the melt, $D$ is the diffusion coefficient, $a_{0}$ is the average distance between volatiles molecules.

After nucleation bubble nuclei grow by $\mathrm{H}_{2} \mathrm{O}$ diffusion, because the concentration of $\mathrm{H}_{2} \mathrm{O}$ at the bubble-melt interface, $C_{\mathrm{R}}$, is lower that the concentration in the surrounding melt, $C_{\mathrm{m}}$. The $\mathrm{H}_{2} \mathrm{O}$ flux into bubbles is given by

$$
q=D\left(\frac{\partial c}{\partial r}\right)_{r=R},
$$

where $D$ is diffusion coefficient, $r$ is the distance from bubble's center, $R$ is bubble radius, and $c$ is the water concentration in the surrounding melt given by

$$
\frac{\partial c}{\partial t}+\frac{d R}{d t} \frac{\partial c}{\partial z}=\frac{1}{r^{2}} \frac{\partial c}{\partial r}\left(D r^{2} \frac{\partial c}{\partial r}\right)
$$

At low supersaturation pressure the left hand side in equation (19) can be neglected [45] and the concentration gradient at the melt-vapor interface can be approximated as

$$
\left(\frac{\partial c}{\partial r}\right)_{r=R}=\frac{C_{\mathrm{m}}-C_{\mathrm{R}}}{R} .
$$

The mass of $\mathrm{H}_{2} \mathrm{O}$ inside bubbles, $m_{\mathrm{g}}$, will increase due to diffusion at a rate

$$
\frac{d m_{\mathrm{g}}}{d t}=\left(4 \pi \mu_{2}\right) \rho_{\mathrm{m}} q,
$$

whereas the bubble growth rate is given by [46]

$$
G(\hat{R})=\frac{\hat{R}}{4 \eta}\left(p_{\mathrm{g}}-p_{\mathrm{m}}-\frac{2 \gamma}{\hat{R}}\right),
$$

where the inertia terms are neglected [10]. Here $\eta$ is the viscosity of melt, $p_{\mathrm{g}}$ is the pressure the $\mathrm{H}_{2} \mathrm{O}$ fluid (vapor) inside bubbles, estimated using the equation of state for $\mathrm{H}_{2} \mathrm{O}$.

\subsubsection{Above fragmentation}

After fragmentation we assume bubbles that bubbles no longer nucleate or grow [37]. In other words, $J=0$ and $G(\hat{R})=0 . \mathrm{H}_{2} \mathrm{O}$, however, continues to exsolve into bubbles with a rate given by equation (18). Exsolved $\mathrm{H}_{2} \mathrm{O}$ escapes by permeable flow from within the pyroclasts into the gas phase surrounding the pyroclasts. Consequently, the gas pressure within pyroclasts decreases at a rate of

$$
\frac{d p_{\mathrm{g}}}{d t}=\frac{p_{\mathrm{m}}-p_{\mathrm{g}}}{\tau_{k}},
$$

where $\tau_{k}$ is the characteristic time scale for permeable outgassing estimated from Darcy's law as

$$
\tau_{\mathrm{k}}=\frac{l^{2}}{k /\left(\eta_{\mathrm{g}} \beta \phi\right)} .
$$

Here $l \approx 10 \mathrm{~cm}$ is the characteristics length scale [37], $k \approx 10^{-12} \mathrm{~m}^{2}$ is permeability [35], $\eta_{\mathrm{g}}=10^{-5} \mathrm{~Pa} . \mathrm{s}$ is viscosity of the gas phase, and $\beta$ is the compressibility of the gas phase, and $\phi$ is porosity of bubbles in the pyroclasts.

Lastly, the concentration of dissolved $\mathrm{H}_{2} \mathrm{O}$ and thus the saturation pressure, both below and above fragmentation, decrease as a result of the diffusion of water into bubbles. The resultant conservation of $\mathrm{H}_{2} \mathrm{O}$ requires that

$$
\frac{d p_{\mathrm{sat}}}{d t} \propto \frac{d C_{\mathrm{m}}}{d t}=-\frac{1}{\rho_{l}}\left(M_{0} \frac{d m_{\mathrm{g}}}{d t}+J m_{\mathrm{c}}\right),
$$

where $\rho_{\mathrm{l}}$ is the melt density, assumed to be constant throughout magma decompression, and $m_{\mathrm{c}}$ is the mass of a bubble nuclei estimated from equation of state.

\subsection{Model simulation}

The parameters in the governing system of equations are either specified or calculated from existing formulations: $\mathrm{H}_{2} \mathrm{O}$ solubility [47], diffusion coefficient [48], equation of state [2], fugacity coefficient [2], surface tension [27], melt viscosity [12], and the molecular volume of $\mathrm{H}_{2} \mathrm{O}$ [1]. For a given simulation we integrated equations (7), (10), (11) for $k=1$ through 3 , as well as equations (23) and (25) using the ode15s function of MATLAB ${ }^{\circledR}$. The boundary condition at the initial depth, $z_{0}$, are

$$
\begin{aligned}
p_{\mathrm{m}}\left(z_{0}\right) & =\rho_{\mathrm{r}} g z_{0}, \\
C_{\mathrm{m}}\left(z_{0}\right) & =C_{\mathrm{eq}}\left(p_{\mathrm{m}}\left(z_{0}\right)\right), \\
\mu_{k}\left(z_{0}\right) & =N_{0} R_{0}^{k} .
\end{aligned}
$$

Here $\rho_{\mathrm{r}}=2400 \mathrm{~kg} / \mathrm{m}^{3}$ is the rock density, $C_{\text {eq }}$ are the equilibrium water concentration, and $N_{0}$ and $R_{0}$ are the number density and radius of pre-existing bubbles. The boundary conditions at the surface are

$$
\begin{gathered}
p_{\mathrm{m}}(z=0)=p_{\mathrm{atm}}, \\
\quad \text { or } \\
M(z=0)=1 .
\end{gathered}
$$

We assume magma fragments at a critical porosity, $\phi_{\mathrm{cr}}$. For each simulation run, we vary $\phi_{\mathrm{cr}}$ to meet the boundary condition at the surface. We estimate bubble size distribution for each simulation by post-processing the simulation results. We discretize $z$ into multiple bins and estimate number of bubbles nucleated at each bin as

$$
N_{\mathrm{m}}(\bar{z})=\int_{\bar{z}}^{\bar{z}+d \bar{z}} \frac{J}{u} d z .
$$

and the final size of bubbles nucleated at each bin as [36]

$$
L_{\mathrm{m}}(\bar{z})=2\left(R_{\mathrm{c}}(\bar{z})+\int_{\bar{z}}^{0} \frac{G(\hat{R})}{u} d z\right) .
$$


The objective of our model is to find conditions at which bubble nucleation is continuous from nucleation onset until magma fragmentation. Nucleation is driven by supersaturation pressure, $p_{\text {sat }}-p_{\mathrm{m}}$ and is thus controlled by the competition between decompression rate, $d p_{\mathrm{m}} / d t$ and $d p_{\text {sat }} / d t$. The latter is proportional to the diffusion rate and is estimated from equation (25). To maintain sufficient supersaturation for nucleation, we assume that the decompression rate at any given depth is greater than diffusion rate, that is

$$
\left(\frac{d p_{\mathrm{m}}}{d t}\right)\left(\frac{d p_{\mathrm{sat}}}{d t}\right)^{-1}=\lambda,
$$

where $\lambda>1$ is a constant. This approach requires that $d p_{\text {sat }} / d t>0$, that is sufficient number of bubbles are nucleated, to be able to estimate decompression rate. We use equation (30) at minimum bubble number density of $1 \mathrm{~mm}^{-3}$. From decompression rate we estimate conduit cross sectional area, $d A / d z$ from equation (7) analogous to the approach in Mastin and Ghiorso [33]. After finding an initial conduit radius we used the MATLAB ${ }^{\circledR}$ pchip function to smooth the obtained function and assess the sensitivity of model predictions to variations in conduit radius.

\subsection{Nucleation time scale in experiments}

Bubble nucleation is driven by supersaturation pressure, $\Delta P_{\mathrm{ss}}=P_{\mathrm{sat}}-P$, defined as the difference between pressure at which $\mathrm{H}_{2} \mathrm{O}$ would be saturated and the sample's pressure, $P . \Delta P_{\text {ss }}$ increases as $P$ decreases. Considering that diffusion is ineffective during decompression [27], $P_{\text {sat }}$ is expected to remain the same as the initial pressure, $P_{\mathrm{i}}$, throughout decompression. $\Delta P_{\mathrm{ss}}$ thus reaches the maximum potential supersaturation pressure when sample pressure reaches the final pressure, $\Delta P_{\mathrm{ss}}=\Delta P_{\max }$, Supplementary Figure 1. Consequently, the nucleation rate in the experiments is expected to increases as sample pressure decreases toward $P_{\mathrm{f}}$, because $\Delta P_{\mathrm{ss}} \approx \Delta P$ and nucleation rate scales as $\exp \left(-1 / \Delta P_{\mathrm{ss}}^{2}\right)$ [11]. Nucleation rate reaches a maximum value at $P_{\mathrm{f}}$ and nucleation continues at this rate until the sample is quenched, unless at some point diffusion becomes non-negligible. Thus, the majority of bubbles are expected to nucleate once $\Delta P$ has reached its maximum $\Delta P_{\max }=P_{\mathrm{i}}-P_{\mathrm{f}}$. If (and once) enough bubbles have nucleated to decrease the characteristic diffusion time to the point where water diffusion into existing bubbles becomes non-negligible, then $\Delta P_{\mathrm{ss}}<\Delta P_{\max }$ and nucleation rate decreases.

We used the nucleation model described in Yamada et al. [26] to quantify nucleation rate during samples hold time from observed bubble number densities. The model was obtained by analytical solution of bubble nucleation and growth formulations described in Toramaru [10] Nucleation rate, $J(t)$, as a function of time is given by

$$
J(t)=J_{\mathrm{s}} \exp \left(-(t / \tau)^{5 / 2}\right) .
$$

Here $t$ is time at the final pressure, $J_{\mathrm{s}}$ is the steady nucleation rate and $\tau$ is the nucleation time scale, which is the e-folding time of nucleation. $\tau_{\mathrm{n}}$ scales inversely with $J_{\mathrm{s}}$ as [26]

$$
\tau=k_{\tau} \times J_{\mathrm{s}}^{-2 / 5} .
$$

The coefficient $k_{\tau}$ depends on melt properties, in particular the diffusion coefficient. Here we assume it is constant because the variability of $k_{\tau}$ across the conditions of our experiments is relatively weak [26].

Integration of $J(t)$ through time yields the bubble number density that are nucleated during annealing time as a function of time, $\hat{N_{\text {post }}}(t)$, given by

$$
N_{\text {post }}(t)=\int_{0}^{t} J\left(t^{\prime}\right) d t^{\prime}=\Gamma\left(\frac{7}{5}\right) J_{\mathrm{s}} \tau \Gamma\left(\frac{2}{5},(t / \tau)^{5 / 2}\right),
$$

$N_{\text {post }}=N_{\mathrm{m}}+N_{0}$ is related to observed bubble number densities where $N_{0}$ is the bubble number density at time $t=0$. In our experiments $N_{0}$ accounts for bubbles that were nucleated during decompression and is obtained for each suite from $N_{\mathrm{m}}$ in samples with $t_{\text {post }}=0$. Furthermore, $\Gamma(x)$ is the gamma function

$$
\Gamma(x)=\int_{0}^{\infty} z^{x-1} \mathrm{e}^{-z} d z
$$

and $\Gamma(s, x)$ is the normalized lower incomplete gamma function,

$$
\Gamma(s, x)=\frac{1}{\Gamma(s)} \int_{0}^{x} z^{s-1} \mathrm{e}^{-z} d z,
$$

Both $\Gamma(x)$ and $\Gamma(s, x)$ arise out of the integration of $J(t)$ (Equation 31).

At the nucleation time scale, $t \gg \tau_{\mathrm{n}}$, nucleation rate decreases and bubble number density eventually reaches the equilibrium value of

$$
N_{\mathrm{eq}}=N_{\text {post }}(t \rightarrow \infty)=\Gamma\left(\frac{7}{5}\right) J_{\mathrm{s}} \tau
$$

Lastly, the predicted non-dimensional bubble number density is estimated from equations (33) and (36)

$$
\frac{N_{\text {post }}(t)}{N_{\mathrm{eq}}}=\Gamma\left(\frac{2}{5},(t / \tau)^{5 / 2}\right)
$$

\section{ACKNOWLEDGEMENTS}

This material is based upon work supported by the National Science Foundation grants EAR-1348072 and EAR-1348050.

\section{AUthor CONTRIBUtion}

S.H. carried out the numerical simulations. J.E.G did the experiments. S.H., H.M.G. and J.E.G. involved in interpretation of the results and preparing the manuscript.

\section{Data AVAILABILITY}

The data used are listed in the references. All equations in the numerical simulation are presented in the Methods.

\section{COMPETING INTERESTS}

The authors declare no competing interests.

\section{REFERENCES}

[1] F. A. Ochs and R. A. Lange. The density of hydrous magmatic liquids. Science, 283:1314-1317, 1999. doi: 10.1126/science.283.5406.1314.

[2] J. R. Holloway. Fugacity and activity of molecular species in supercritical fluids. Springer Netherlands, Dordrecht, Netherlands, 1977. doi: 10.1007/978-94-010-1252-2\@9.

[3] L. Wilson, R. S. J. Sparks, and G. P. L. Walker. Explosive volcanic eruptions - IV. The control of magma properties and conduit geometry on eruption column behaviour. Geophysical Journal International, 63:117-148, 1980. doi: 10.1111/j.1365-246X.1980.tb02613.x.

[4] Helge M. Gonnermann and Michael Manga. The fluid mechanics inside a volcano. Annual Review of Fluid Mechanics, 39(1):321-356, jan 2007. ISSN 0066-4189. doi: 10.1146/annurev.fluid.39.050905.110207. 
[5] SharonL. Webb and DonaldB. Dingwell. The onset of non-Newtonian rheology of silicate melts. Physics and Chemistry of Minerals, 17(2):125-132, mar 1990. ISSN 0342-1791. doi: 10.1007/BF00199663.

[6] D. B. Dingwell. Volcanic Dilemma-Flow or Blow? Science, 273(5278):1054-1055, 1996.

[7] Helge M. Gonnermann. Magma Fragmentation. Annual Review of Earth and Planetary Sciences, 43(1):431-458, 2015. doi: 10.1146/annurev-earth-060614-105206.

[8] R. Stephen J. Sparks. The dynamics of bubble formation and growth in magmas: A review and analysis. Journal of Volcanology and Geothermal Research, 3(1-2):1-37, mar 1978. ISSN 03770273. doi: 10.1016/0377-0273(78) 90002-1.

[9] Alfre a. Prousevitch, D. L. Sahagian, and Alfred T. Anderson. Dynamics of diffusive bubble growth in magmas: Isothermal case. Journal of Geophysical Research: Solid Earth, 98(B12):22283-22307, dec 1993. doi: 10.1029/ 93JB02027.

[10] A. Toramaru. Numerical study of nucleation and growth of bubbles in viscous magmas. Journal of Geophysical Research: Solid Earth, 100:1913-1931, 1995. doi: 10. 1029/94JB02775.

[11] O. Navon and V. Lyakhovsky. Vesiculation processes in silicic magmas. In J. S. Gilbert and R. S. J. Sparks, editors, The physics of explosive volcanic eruptions, pages 27-50. Geological Society, London, Special Publications, Cambridge, UK, 1998.

[12] H. Hui and Y. Zhang. Toward a general viscosity equation for natural anhydrous and hydrous silicate melts. Geochimica et Cosmochimica Acta, 71:403-416, 2007. doi: 0.1016/j.gca.2006.09.003.

[13] A. Toramaru. BND (bubble number density) decompression rate meter for explosive volcanic eruptions. Journal of Volcanology and Geothermal Research, 154:303-316, 2006. doi: 10.1016/j.jvolgeores.2006.03.027.

[14] C. Klug, K. V. Cashman, and C. Bacon. Structure and physical characteristics of pumice from the climactic eruption of Mount Mazama (Crater Lake), Oregon. Bulletin of Volcanology, 64:486-501, 2002. doi: 10.1007/ s00445-002-0230-5.

[15] N. K. Adams, B. F. Houghton, and W. Hildreth. Abrupt transitions during sustained explosive eruptions: examples from the 1912 eruption of Novarupta, Alaska. Bulletin of Volcanology, 69:189-206, 2006. doi: 10.1007/ s00445-006-0067-4.

[16] R. J. Carey, B. F. Houghton, and T. Thordarson. Abrupt shifts between wet and dry phases of the 1875 eruption of Askja Volcano: Microscopic evidence for macroscopic dynamics. Journal of Volcanology and Geothermal Research, 184:256-270, 2009. doi: 10.1016/j.jvolgeores.2009.04. 003.

[17] Thomas Shea, Lucia Gurioli, Jessica F. Larsen, Bruce F. Houghton, Julia E. Hammer, and Katharine V. Cashman. Linking experimental and natural vesicle textures in Vesuvius 79AD white pumice. Journal of Volcanology and Geothermal Research, 192(1-2):69-84, apr 2010. doi: 10.1016/j.jvolgeores.2010.02.013.
[18] T. Giachetti, T.H. Druitt, Alain Burgisser, L. Arbaret, and C. Galven. Bubble nucleation, growth and coalescence during the 1997 Vulcanian explosions of Soufrière Hills Volcano, Montserrat. Journal of Volcanology and Geothermal Research, 193(3-4), 2010. doi: 10.1016/j.jvolgeores. 2010.04.001.

[19] F. Alfano, C. Bonadonna, and L. Gurioli. Insights into eruption dynamics from textural analysis: the case of the May, 2008, Chaitén eruption. Bulletin of Volcanology, 74: 2095-2108, 2012. doi: 10.1007/s00445-012-0648-3.

[20] Margaret T. Mangan and Katharine V. Cashman. The structure of basaltic scoria and reticulite and inferences for vesiculation, foam formation, and fragmentation in lava fountains. Journal of Volcanology and Geothermal Research, 73(1-2):1-18, sep 1996. ISSN 03770273. doi: 10.1016/0377-0273(96)00018-2.

[21] J.D. Blower, J.P. Keating, H. M. Mader, and J.C. Phillips. The evolution of bubble size distributions in volcanic eruptions. Journal of Volcanology and Geothermal Research, 120(1-2):1-23, 2002. ISSN 03770273. doi: 10.1016/S0377-0273(02)00404-3.

[22] Thomas Shea, Bruce F. Houghton, Lucia Gurioli, Katharine V. Cashman, Julia E. Hammer, and Barbara J. Hobden. Textural studies of vesicles in volcanic rocks: An integrated methodology. Journal of Volcanology and Geothermal Research, 190(3-4):271-289, 2010. ISSN 03770273. doi: 10.1016/j.jvolgeores.2009.12.003.

[23] Helge M. Gonnermann and B. F. Houghton. Magma degassing during the Plinian eruption of Novarupta, Alaska, 1912. Geochemistry, Geophysics, Geosystems, 13(10): n/a-n/a, oct 2012. ISSN 15252027. doi: 10.1029/ 2012 GC004273.

[24] T. Shea. Bubble nucleation in magmas: A dominantly heterogeneous process? Journal of Volcanology and Geothermal Research, 343:155-170, 2017. doi: 10.1016/j. jvolgeores.2017.06.025.

[25] Sahand Hajimirza, Helge M. Gonnermann, and James E. Gardner. Eruptive dynamics in plinian silicic eruptions. 2020.

[26] Kou Yamada, Hidekazu Tanaka, Kiyoshi Nakazawa, and Hiroyuki Emori. A new theory of bubble formation in magma. Journal of Geophysical Research: Solid Earth, 110(2):1-17, 2005. ISSN 21699356. doi: 10.1029/ 2004JB003113.

[27] S. Hajimirza, H. M. Gonnermann, J. E. Gardner, and T. Giachetti. Predicting homogeneous bubble nucleation in rhyolite. Journal of Geophysical Research: Solid Earth, 124:2395-2416, 2019. doi: 10.1029/2018JB015891.

[28] M. T. Mangan and T. Sisson. Delayed, disequilibrium degassing in rhyolite magma: decompression experiments and implications for explosive volcanism. Earth and Planetary Science Letters, 183:441-455, 2000. doi: 10.1016/S0012-821X(00)00299-5.

[29] C. C. Mourtada-Bonnefoi and D. Laporte. Homogeneous bubble nucleation in rhyolitic magmas: An experimental study of the effect of $\mathrm{H} 2 \mathrm{O}$ and $\mathrm{CO} 2$. Journal of Geophysical Research: Solid Earth, 107(B4):ECV 2-1-ECV 2-19, 2002. doi: 10.1029/2001JB000290. 
[30] T. Giachetti, H. M. Gonnermann, J. E. Gardner, A. Burgisser, S. Hajimirza, T. C. Earley, N. Truong, and P. Toledo. Bubble Coalescence and Percolation Threshold in Expanding Rhyolitic Magma. Geochemistry, Geophysics, Geosystems, 20:1054-1074, 2019. doi: 10.1029/2018GC008006.

[31] H. M. Gonnermann and J. E. Gardner. Homogeneous bubble nucleation in rhyolitic melt: Experiments and nonclassical theory. Geochemistry, Geophysics, Geosystems, 14(11):4758-4773, 2013. doi: 10.1002/ggge.20281.

[32] P. J. Wallace, T. Plank, M. Edmonds, and E. H. Hauri. Chapter 7 - volatiles in magmas. In H. Sigurdsson, B. Houghton, S. McNutt, R. Hazel, and J. Stix, editors, The Encyclopedia of Volcanoes (Second Edition), pages 163 - 183. Academic Press, Amsterdam, 2015. doi: 10.1016/B978-0-12-385938-9.00007-9.

[33] Larry G. Mastin and Mark S. Ghiorso. A numerical program for steady-state flow of magma-gas mixtures through vertical eruptive conduits. Technical report, Department of the Interior, Washington DC, 2000.

[34] David Bercovici and Chloé Michaut. Two-phase dynamics of volcanic eruptions: Compaction, compression and the conditions for choking. Geophysical Journal International, 182(2):843-864, 2010. doi: 10.1111/j.1365-246X.2010. 04674.x.

[35] Helge M. Gonnermann, Thomas Giachetti, Céline Fliedner, Chinh T. Nguyen, Bruce F. Houghton, Joshua A. Crozier, and Rebecca J. Carey. Permeability During Magma Expansion and Compaction. Journal of Geophysical Research: Solid Earth, pages 1-15, 2017. ISSN 21699313. doi: 10.1002/2017JB014783.

[36] H. Massol and T. Koyaguchi. The effect of magma flow on nucleation of gas bubbles in a volcanic conduit. Journal of Volcanology and Geothermal Research, 143:69-88, 2005. doi: 10.1016/j.jvolgeores.2004.09.011.

[37] A. C. Rust and K. V. Cashman. Permeability controls on expansion and size distributions of pyroclasts. Journal of Geophysical Research: Solid Earth, 116(11):1-17, 2011. ISSN 21699356. doi: 10.1029/2011JB008494.

[38] M. Cassidy, M. Manga, K. V. Cashman, and O. Bachmann. Controls on explosive-effusive volcanic eruption styles. Nature Communications, 9:2839, 2018. doi: 10.1038/ s41467-018-05293-3.

[39] Madison L. Myers, Paul J. Wallace, Colin J.N. Wilson, James M. Watkins, and Yang Liu. Ascent rates of rhyolitic magma at the onset of three caldera-forming eruptions. American Mineralogist, 103(6):952-965, 2018. ISSN 19453027. doi: 10.2138/am-2018-6225.

[40] Marie Edmonds and Andrew W. Woods. Exsolved volatiles in magma reservoirs. Journal of Volcanology and Geothermal Research, 368:13-30, 2018. ISSN 03770273. doi: 10.1016/j.jvolgeores.2018.10.018.

[41] Yu B. Slezin. The mechanism of volcanic eruptions (a steady state approach). Journal of Volcanology and Geothermal Research, 122(1-2):7-50, 2003. ISSN 03770273. doi: 10.1016/S0377-0273(02)00464-X.

[42] N. Cluzel, D. Laporte, A. Provost, and I. Kannewischer. Kinetics of heterogeneous bubble nucleation in rhyolitic melts: implications for the number density of bubbles in volcanic conduits and for pumice textures. Contributions to Mineralogy and Petrology, 156:745-763, 2008. doi: 10.1007/s00410-008-0313-1.

[43] S. Hurwitz and O. Navon. Bubble nucleation in rhyolitic melts: Experiments at high pressure, temperature, and water content. Earth and Planetary Science Letters, 122: 267-280, 1994. doi: 10.1016/0012-821X(94)90001-9.

[44] J. E. Gardner and M. Denis. Heterogeneous bubble nucleation on Fe-Ti oxide crystals in high-silica rhyolitic melts. Geochimica et Cosmochimica Acta, 68:3587-3597, 2004. doi: 10.1016/j.gca.2004.02.021.

[45] A. A. Chernov, V. K. Kedrinsky, and A. A. Pil'nik. Kinetics of gas bubble nucleation and growth in magmatic melt at its rapid decompression. Physics of Fluids, 26(11), 2014. ISSN 10897666. doi: 10.1063/1.4900846.

[46] M S Plesset and A Prosperetti. Bubble Dynamics and Cavitation. Annual Review of Fluid Mechanics, 9(1):145185, jan 1977. ISSN 0066-4189. doi: 10.1146/annurev.fl. 09.010177.001045.

[47] Y. Liu, Y. Zhang, and H. Behrens. Solubility of $\mathrm{H}_{2} \mathrm{O}$ in rhyolitic melts at low pressures and a new empirical model for mixed $\mathrm{H}_{2} \mathrm{O}-\mathrm{CO}_{2}$ solubility in rhyolitic melts. Journal of Volcanology and Geothermal Research, 143:219-235, 2005. doi: 10.1016/j.jvolgeores.2004.09.019.

[48] Y. Zhang and $\mathrm{H}$. Behrens. $\mathrm{H}_{2} \mathrm{O}$ diffusion in rhyolitic melts and glasses. Chemical Geology, 169:243-262, 2000. doi: 10.1016/s0009-2541(99)00231-4. 
PREPRINT - THE SHAPE OF VOLCANIC CONDUITS INFERRED FROM BUBbLE SIZE DISTRIBUTIONS

Supplementary Materials 
Supplementary Table 1: Experimental conditions and results. $P_{\mathrm{i}}$ and $P_{\mathrm{f}}$ are initial and final pressures, $T$ is temperature, $t_{\mathrm{h}}$ is hydration duration, $t_{\mathrm{d}}$ is decompression time, $t_{\mathrm{p}}$ is sample hold time before quench, $\left[\mathrm{H}_{2} \mathrm{O}\right]$ is dissolved water concentration and $N_{\mathrm{m}}$ is bubble number density. ${ }^{a}$ Experiments were discussed in Gonnermann and Gardner [31]. ${ }^{b}$ Experiments were discussed in Hajimirza et al. [27]. ${ }^{c}$ Experiments were discussed in Giachetti et al. [30]. ${ }^{d}$ Experiments were discussed in ? ]. ${ }^{e}$ Outliers. 5 out of 35 decompression experiments are considered as outliers because they have a considerably different $N_{\mathrm{m}}$ comparing to $N_{\mathrm{m}}$ in experiments within the same suite.

\begin{tabular}{|c|c|c|c|c|c|c|c|c|c|}
\hline Run & $\begin{array}{l}\text { Sarting } \\
\text { material }\end{array}$ & $\begin{array}{c}P_{\mathrm{i}} \\
(\mathrm{MPa})\end{array}$ & $\begin{array}{c}P_{\mathrm{f}} \\
(\mathrm{MPa})\end{array}$ & $\begin{array}{c}T \\
\left({ }^{\circ} \mathrm{C}\right) \\
\end{array}$ & $\begin{array}{c}t_{\mathrm{h}} \\
(\mathrm{hr})\end{array}$ & $\begin{array}{c}t_{\mathrm{d}} \\
(\mathrm{s})\end{array}$ & $\begin{array}{l}t_{\text {post }} \\
\text { (s) }\end{array}$ & $\begin{array}{l}{\left[\mathrm{H}_{2} \mathrm{O}\right]} \\
(\mathrm{wt} \%)\end{array}$ & $\begin{array}{c}N_{\mathrm{m}} \\
\left(m^{-3}\right)\end{array}$ \\
\hline \multicolumn{10}{|c|}{ Hydration experiments } \\
\hline $\mathrm{G}-885^{a}$ & Rhyolite & 160 & 160 & 875 & 120 & - & - & $5.00 \pm 0.01$ & - \\
\hline G-595 ${ }^{a}$ & Rhyolite & 160 & 160 & 875 & 120 & - & - & $4.93 \pm 0.13$ & - \\
\hline $\mathrm{G}-1594 \mathrm{~A}^{b}$ & Rhyolite & 160 & 160 & 875 & 118 & - & - & $4.79 \pm 0.01$ & - \\
\hline $\mathrm{G}-1607^{b}$ & Rhyolite & 160 & 160 & 875 & 121 & - & - & $4.85 \pm 0.08$ & \\
\hline $\mathrm{G}-876^{a}$ & Rhyolite & 160 & 160 & 875 & 120 & - & - & $5.08 \pm 0.01$ & - \\
\hline G-1780 & Rhyolite & 160 & 160 & 850 & 173 & - & - & $5.02 \pm 0.13$ & - \\
\hline G-1770 & Rhyolite & 190 & 190 & 850 & 173 & - & - & $6.03 \pm 0.09$ & - \\
\hline G-1771 & Rhyolite & 190 & 190 & 850 & 173 & - & - & $6.01 \pm 0.11$ & - \\
\hline G-1570 & Rhyolite & 190 & 190 & 850 & 168 & - & - & $5.53 \pm 0.01$ & - \\
\hline G-1579 & Rhyolite & 190 & 190 & 850 & 168 & - & - & $5.45 \pm 0.11$ & - \\
\hline G-1731 & Rhyolite & 190 & 190 & 850 & 169 & - & - & $5.69 \pm 0.06$ & - \\
\hline G-1736 & Rhyolite & 190 & 190 & 850 & 163 & - & - & - & - \\
\hline G-1779 & Rhyolite & 190 & 190 & 850 & 168 & - & - & $5.68 \pm 0.02$ & - \\
\hline G-1778 & Rhyolite & 190 & 190 & 850 & 168 & - & - & $5.91 \pm 0.09$ & - \\
\hline $\mathrm{G}-1594 \mathrm{~B}^{b}$ & Rhyolite & 200 & 200 & 875 & 118 & - & - & $5.51 \pm 0.03$ & - \\
\hline $\mathrm{G}-1608^{c}$ & Rhyolite & 200 & 200 & 875 & 123 & - & - & $5.48 \pm 0.04$ & - \\
\hline G- $1457^{c}$ & Rhyolite & 200 & 200 & 850 & 144 & - & - & $5.71 \pm 0.02$ & - \\
\hline $\mathrm{G}-1456^{c}$ & Rhyolite & 200 & 200 & 850 & 145 & - & - & $5.70 \pm 0.01$ & - \\
\hline $\mathrm{G}-1483^{c}$ & Rhyolite & 200 & 200 & 850 & 216 & - & - & $5.50 \pm 0.08$ & - \\
\hline G- $1608^{c}$ & Rhyolite & 200 & 200 & 850 & 123 & - & - & $5.48 \pm 0.04$ & - \\
\hline $\mathrm{G}-1680^{d}$ & Rhyolite & 250 & 250 & 850 & 167 & - & - & $6.45 \pm 0.08$ & - \\
\hline G-1591 ${ }^{d}$ & Rhyolite & 250 & 250 & 850 & 167 & - & - & - & - \\
\hline G-1732 & Rhyolite & 250 & 250 & 850 & 172 & _ & _ & $6.45 \pm 0.08$ & _ \\
\hline G-1742 & Rhyolite & 250 & 250 & 850 & 165 & - & - & $6.90 \pm 0.06$ & - \\
\hline G-1741 ${ }^{d}$ & Rhyolite & 250 & 250 & 850 & 159 & - & - & $7.30 \pm 0.7$ & - \\
\hline \multicolumn{10}{|c|}{ Decompression experiments } \\
\hline $\mathrm{G}-1614^{b}$ & G-1594A & 161 & 13 & 875 & - & 10 & 0 & - & $1.0 \times 10^{9}$ \\
\hline $\mathrm{G}-1616^{b}, e$ & G-1594A & 161 & 11 & 875 & - & 15 & 5 & - & $1.1 \times 10^{9}$ \\
\hline $\mathrm{G}-1627^{b}$ & G-1607 & 161 & 13 & 875 & - & 16 & 18 & - & $1.1 \times 10^{10}$ \\
\hline G- $1628^{b}$ & G-1607 & 161 & 11 & 875 & - & 11 & 29 & - & $2.7 \times 10^{10}$ \\
\hline G-1796 & G-1780 & 161 & 11 & 875 & - & 11 & 60 & - & $7.1 \times 10^{9}$ \\
\hline $\mathrm{G}-608^{a}$ & G-595 & 161 & 13 & 875 & - & 11 & 109 & - & $3.2 \times 10^{10}$ \\
\hline G-1746 & G-1736 & 190 & 60 & 850 & - & 54 & 0 & - & $2.4 \times 10^{8}$ \\
\hline G-1776 & G-1771 & 190 & 58 & 850 & - & 48 & 9 & - & $9.4 \times 10^{8}$ \\
\hline W-6 & G-1731 & 190 & 60 & 850 & - & 47 & 10 & - & $9.9 \times 10^{8}$ \\
\hline G-1794 & G-1731 & 190 & 60 & 850 & - & 44 & 22 & - & $1.5 \times 10^{9}$ \\
\hline $\mathrm{W}-7^{e}$ & G- 1570 & 190 & 60 & 850 & - & 55 & 25 & - & $3.4 \times 10^{10}$ \\
\hline G-1798 & G-1779 & 190 & 59 & 850 & _ & 40 & 23 & - & $1.3 \times 10^{9}$ \\
\hline G-1799 & G-1779 & 190 & 59 & 850 & - & 50 & 30 & - & $2.8 \times 10^{9}$ \\
\hline G-1793 & G-1778 & 190 & 60 & 850 & - & 47 & 44 & - & $2.5 \times 10^{9}$ \\
\hline $\mathrm{W}-8^{e}$ & G-1579 & 190 & 60 & 850 & - & 55 & 50 & - & $8 \times 10^{8}$ \\
\hline G-1747 & G-1736 & 190 & 46 & 850 & - & 3 & 0 & - & $4.8 \times 10^{9}$ \\
\hline $\mathrm{W}-9^{e}$ & G-1579 & 190 & 46 & 850 & - & 3 & 10 & - & $3 \times 10^{9}$ \\
\hline G-1777 & G-1771 & 190 & 42.5 & 850 & - & 2 & 15 & - & $4.4 \times 10^{11}$ \\
\hline G-1774 & G-1770 & 190 & 42.5 & 850 & - & 2 & 21 & - & $6.2 \times 10^{11}$ \\
\hline G-1775 & G- 1770 & 190 & 42 & 850 & - & 1 & 41 & - & $6.9 \times 10^{11}$ \\
\hline W-10 & G-1731 & 190 & 46 & 850 & - & 3 & 50 & - & $1 \times 10^{12}$ \\
\hline $\mathrm{G}-1617^{b}$ & G-1594B & 201 & 75 & 875 & - & 45 & 0 & - & $1.0 \times 10^{8}$ \\
\hline $\mathrm{G}-1620^{b}$ & G-1594B & 201 & 74 & 875 & - & 28 & 12 & - & $8.0 \times 10^{8}$ \\
\hline G-1148 & G-1594B & 201 & 74 & 875 & - & 35 & 25 & - & $5.9 \times 10^{9}$ \\
\hline G- $1622^{b}$ & G-1594B & 201 & 75 & 875 & - & 34 & 29 & - & $1.4 \times 10^{9}$ \\
\hline $\mathrm{G}-1632^{b}$ & G-1608 & 201 & 75 & 875 & - & 34 & 56 & - & $2.3 \times 10^{10}$ \\
\hline $\mathrm{G}-1481^{c}$ & G-1457 & 201 & 54 & 850 & - & 2 & 15 & - & $1.2 \times 10^{12}$ \\
\hline $\mathrm{G}-1501^{c}$ & G-1483 & 201 & 54.0 & 850 & - & 1 & 31 & - & $2.6 \times 10^{12}$ \\
\hline $\mathrm{G}-1482^{c}$ & G- 1457 & 201 & 54 & 850 & - & 1 & 60 & - & $2.6 \times 10^{12}$ \\
\hline G- $1484^{c}$ & G- 1456 & 201 & 54 & 850 & _ & 2 & 90 & - & $3.4 \times 10^{12}$ \\
\hline G-1791 & G-1741 & 251 & 134 & 850 & - & 2 & 40 & - & 0 \\
\hline $\mathrm{G}-1685^{d}$ & G-1680 & 251 & 135 & 850 & _- & 2 & 58 & - & $2.1 \times 10^{9}$ \\
\hline G-1797 & G-1742 & 251 & 133 & 850 & - & 3 & 71 & - & $7.1 \times 10^{8}$ \\
\hline $\mathrm{W}-1^{e}$ & G-1591 & 251 & 135 & 850 & - & 3 & 87 & - & $2.9 \times 10^{10}$ \\
\hline W-2 & G-1732 & 251 & 135 & 850 & - & 2 & 118 & - & $1.1 \times 10^{9}$ \\
\hline
\end{tabular}


Supplementary Table 2: Nucleation rate and time scale predicted for each experimental suite.

\begin{tabular}{|c|c|c|c|c|c|}
\hline Experimental suite & $P_{\mathrm{i}}(\mathrm{MPa})$ & $P_{\mathrm{f}}(\mathrm{MPa})$ & $J_{\mathrm{s}}\left(\mathrm{m}^{-3} \mathrm{~s}^{-1}\right)$ & $\tau_{\mathrm{n}}(\mathrm{s})$ & $N_{\mathrm{m}, \text { final }}$ \\
\hline 1 & 200 & 54 & $9.5 \times 10^{10}$ & 33 & $2.8 \times 10^{12}$ \\
2 & 190 & $42-46$ & $2.5 \times 10^{10}$ & 57 & $1.3 \times 10^{12}$ \\
3 & 160 & $10-13$ & $3.5 \times 10^{8}$ & 319 & $9.9 \times 10^{10}$ \\
4 & 200 & $74-75$ & $1.2 \times 10^{8}$ & 482 & $5.1 \times 10^{10}$ \\
5 & 190 & $58-60$ & $6.4 \times 10^{7}$ & 628 & $3.5 \times 10^{10}$ \\
6 & 250 & $132-135$ & $1.5 \times 10^{7}$ & 1120 & $1.5 \times 10^{10}$ \\
\hline
\end{tabular}




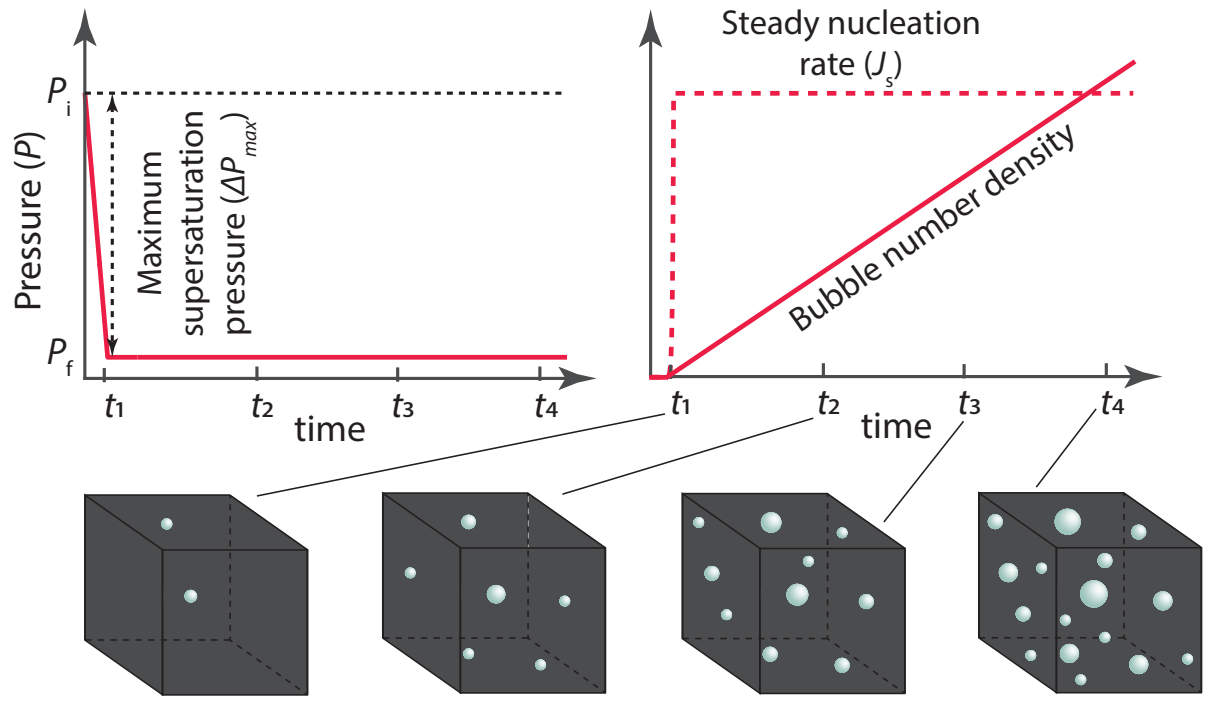

Supplementary Figure 1: Supplementary: Schematic representation of bubble nucleation in during experiments. Samples within a given suite have similar initial and final pressures as well as decompression rates, but are quenched at different times. At the final pressure nucleation continues while the sample remains supersaturated. As a consequence bubble number density increases proportionally to annealing time. 


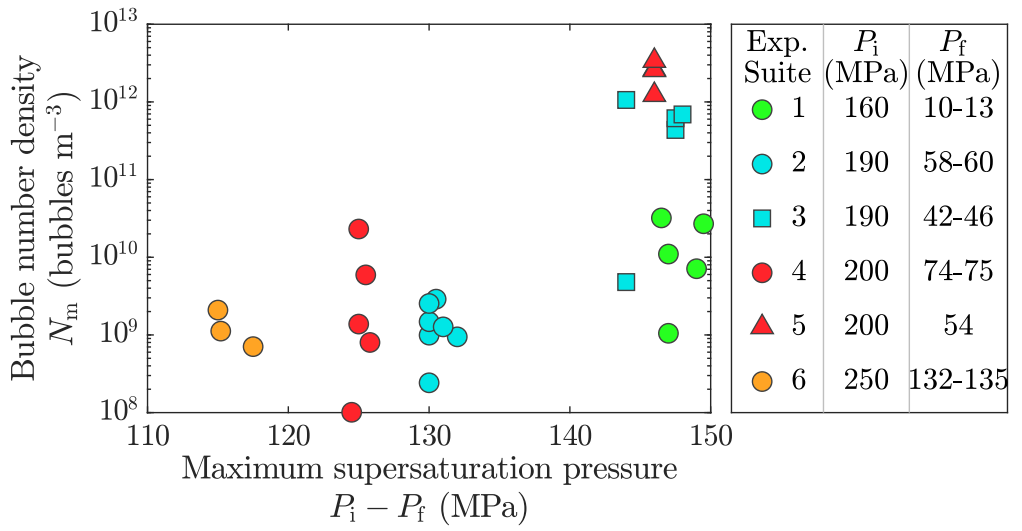

Supplementary Figure 2: Supplementary: Observed bubble number density in experiments as a function of supersaturation pressure. For each experimental suite, characterized by similar decompression and decompression rate, bubble number density varies considerably, in some suites over more than 2 orders of magnitude. 


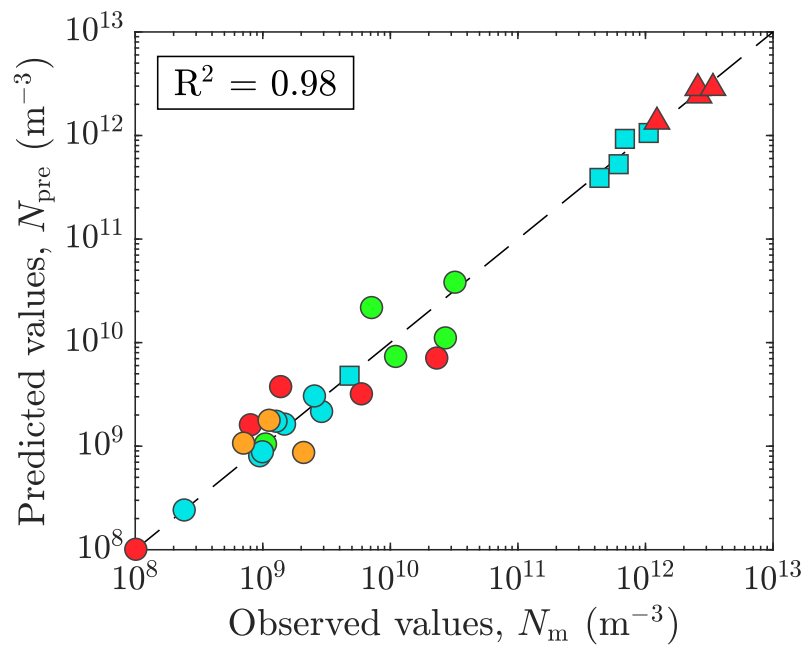

Supplementary Figure 3: Supplementary: Predicted bubble number densities compared with the observed values. The predicted values are from equation 30 in the main text. The dashed line represents 1:1 line. All predicted values are within one order of magnitude of observed bubble number densities. 